\title{
Candido, Antonio y Rama, Ángel. Un Proyecto Latinoamericano, Antonio Can- dido y Ángel Rama, correspondencia. Montevideo:
}

Estuario Editora, 20I6. I7I pp.

\author{
Eduardo Toro \\ Universidade Estadual de Campinas (UNICAMP, \\ Brasil).
}

Nada más público que la correspondencia privada entre intelectuales. Por su naturaleza ambigua, entre lo público y lo privado, este tipo de cartas son documentos llave que denuncian la intimidad de lo público: las disputas ideológicas, las dificultades materiales, así como el afecto entre quienes se corresponden. Toda carta revela un proyecto de futuro, una cierta complicidad, que se legitima con motivo de su respuesta. Ahora bien, más de dos décadas de intercambio epistolar demuestran una afinidad que está más allá del quehacer intelectual. El intercambio epistolar entre Ángel Rama (1926-1983) $y$, el recientemente fallecido, Antonio Candido (1918-2017), compuesto por más de 87 cartas — escritas entre abril de 1960 y octubre de 1983 - publicadas en esta edición—, ${ }^{1}$ - entre abril de 1960 y octubre de 1983-, es ejemplo de ese proceso que estrecha los lazos afectivos

$1 \mathrm{El}$ editor advierte sobre el estado incompleto del acervo epistolar publicado: "Cabe suponer que parte de la veintena de comunicaciones de Rama que no tienen su contrapartida, datadas entre fines 1974 y principios de 1977, podrían hallarse en el archivo de la Biblioteca Ayacucho (...). Otros investigadores más afortunados -que no es el caso de quien suscribe- podrán encontrar en el mencionado archivo de Caracas estas piezas, que en apariencia no son tantas como las que remitiera Ángel Rama” (2016:35). 
a partir de la sintonía intelectual. Con cada intercambio de cartas, el lector que se aproxima a este libro evidencia una apuesta que participa de la construcción de un futuro, un proyecto común que, por su importancia cultural y pertinencia histórica, ha sido intitulado por sus editores como: Un proyecto latinoamericano.

La obra se integra a una bibliografía crítica preocupada una bibliografía crítica preocupada con la vida íntima de la producción intelectual del crítico uruguayo, que inauguró Rosario Peyrou con la publicación de Diario 1974-1983 (Rama, 200I) y queposteriormente fue ampliada por Haydée Ribeiro Coelho y Pablo Rocca al publicar Diálogos latinoamericanos: correspondencia entre Ángel Rama, Berta e Darcy Ribeiro (Rivero y Rama, 2015). Esta vez, Amparo Rama y Pablo Rocca asumieron el arduo trabajo de constituir objetos de archivo en obra: compilar, editar, transcribir y traducir un diálogo (que contó con la revisión de Candido).

La edición, que incluye cartas hasta ahora inéditas, ocupa un lugar fundamental dentro de la historia intelectual latinoamericana, como sostiene Pablo Rocca en su prólogo, donde sintetiza y actualiza su tesis de doctorado Ángel Rama, Emir Rodríguez Monegal y el Brasil (Rocca, 2006). El diálogo entre Ángel Rama y Antonio Candido, según el crítico uruguayo, permite la reflexión sobre las tendencias teóricas que posibilitaron un modelo crítico que insiste en ver la literatura latinoamericana como un sistema integrado, constantemente nutrido por el diálogo autor, obra y público

De a cuerdo con Rocca, desde el primer intercambio epistolar, Rama fue consciente de que los conceptos con los cuales Candido analizaba la literatura de su país, como «formación»y «sistema literario», extrapolaban la idea de lo nacional, dado que proponían herramientas interpretativas para analizar los procesos de «formación» de literaturas en condiciones similares a las del Brasil, como las de América Latina. De allí que el profesor uruguayo rastree en su prólogo elementos que permitieron la consolidación de categorías para comprender la literatura continental y que quedarían registradas en documentos fundamentales como $\mathrm{La}$ ciudad letrada (1984) y Transculturación narrativa (1982).

La sintonía intelectual presentada en el prólogo de Pablo Rocca se revela en las cartas por el paso de un intercambio comedido a una reciprocidad efectiva que vinculó estos dos autores por veintitrés años, durante los cuales establecieron una amistad duradera y abrieron canales de contacto académicos, editoriales y afectivos. Candido dirá sobre Rama en carta escrita en São Paulo el is de mayo de 1973: 
Pocas veces he visto una solución tan fuerte y armoniosa para este difícil problema, que es ver la sociedad desde el ángulo de la literatura y la literatura desde el ángulo de la sociedad, sin paralelismo mecánico, pero de un modo orgánico y vivo. De todo eso resulta una visión política y estética plenamente convincente. Te felicito. $(55)^{2}$

Rama, a su vez refiriéndose a Candido, en carta de Caracas, del 8 de noviembre de 1973 dirá:

Como para mí coincidir contigo es la corroboración de que no me equivoco, te imaginas la alegría que me produjo leerte. Tenía razón yo cuando insistía en que debemos formar ese equipo latinoamericano coherente y serio, de estudiosos, capaces de trabajar a la par de sociólogos y antropólogos, en la tarea de pensar a nuestra cultura y a nuestra América. Como a pesar de que tienes pocos años más que yo eres de algún modo el padre de todo esto, es a ti a quien correspondería poner en marcha ese equipo y con una finalidad concreta e inmediata: reescribir la Historia de la Literatura Latinoamericana, eso que nunca se hizo y que estamos obligados a hacer nosotros. ¡Ojalá nos dé tiempo el señor! (64)

Carta tras carta, la fragilidad material del género epistolar se hace presente. Rama, en carta escrita en Montevideo del I6 de octubre de 1967, afirma: «Utilizo la vieja Caixa Postal de mi agenda para escribirle y me encomiendo a los dioses del Correo, tan inseguros y displicentes como los mortales» (45). Luego, en una carta redactada en Caracas del 17 de abril de 1974, dirá: «mis relaciones con el correo se parecen a las relaciones de los alquimistas con los elementos naturales, son bastante imprevisibles, llenas de sorpresas y voluntades inexplicables» (67). Estos comentarios del autor uruguayo sitúan el intercambio epistolar en un contexto material inmediato, que hoy nos parece distante; en él la escasez de teléfonos y la ausencia de internet hacían del correo postal la herramienta más eficaz para el diálogo en la distancia, esclareciendo un poco las mutables condiciones materiales en las que estos autores tuvieron que construir su obra.

Sin embargo, la relación más efectiva de las cartas con su tiempo se hace presente al descubrir la preocupación latente por el lugar del intelectual intrincado en una realidad política funesta, asumiendo que el exilio y la censura pasaron a ocupar un lugar central en las dictaduras del continente. Es grave la angustia por la realidad política en Brasil, Uruguay, Chile y Argentina, así como es evidente la precaria situación del intelectual lati- 
noamericano. Abundan las menciones. Candido, en carta fechada en SP del 27 de noviembre de 1967 — seis años antes del comienzo de la dictadura cívico-militar en el Uruguay-, ya se mostraba preocupado con el posible destino del país oriental: «Me quedo muy angustiado con las noticias sobre Uruguay y las presiones que sufre de los dos vecinos gigantescos y mal intencionados, ambos con las peores orientaciones políticas» (46).

Con la imposición del régimen militar en Chile, la preocupación, así como la tragedia, solo aumenta, haciéndose más próxima a causa de familiares y amigos. Tanto Rama como Candido coinciden en demostrar su indignación y zozobra; Candido le escribirá a Rama el 30 de septiembre de 1973 desde São Paulo: «Estamos evidentemente arrasados con el caso de Chile, esperando las peores noticias acerca de conocidos y amigos de allá. ¡Qué catástrofe!» (57). Casi simultáneamente y sin haber recibido la carta ya mencionada de Candido, el 7 de octubre del mismo año, Rama escribirá desde Caracas:

Las noticias de Chile son realmente espeluznantes. Casi no se tiene energía para hablar de ellas. Del mismo modo que tengo yo allí familiares en situaciones bien adversas, descuento que les pasará a ustedes lo mismo con amigos y colegas. Es una monstruosa ratonera donde han encerrado a buena parte de lo mejor que tenemos en América. (58)

El caso de Chile no será el único. Sobre la guerra de las Malvinas, Candido escribirá desde Rio de Janeiro el 20 de mayo de 1982: «ESTOY ATERRADO CON LA GUERRA DE LAS MALVINAS Y EVENTUALES CONSECUENCIAS PARA TODOS NOSOTROS! ॥ (I32). A ello, el 3I de mayo del mismo año, Rama responderá desde Washington: «También yo estoy inquieto de la guerra de Malvinas, aunque secretamente esperanzado: la insensatez (de los repugnantes militares argentinos y de la no menos repugnante Sra. Thatcher) se pagará cara, pero confío que también abrirá los ojos de nuestros pueblos» (80).

La intromisión de la catástrofe política en el quehacer intelectual de estos autores transita entre lo público, por medio de la censura, y lo privado, a través del exilio. En carta del 7 de septiembre de 1975 , Candido denuncia: ${ }^{4}$

El Supremo Tribunal Federal no hizo lugar a la petición de Argumento, pasando por encima no solo de la ley, sino también de la decencia. Se trata de una decisión histórica, 
que dejó prácticamente el camino libre para que las autoridades policiales usen los poderes excepcionales del Presidente contra publicaciones de cualquier tipo. Redactamos una carta de protesta, pero los periódicos no la publicaron. Cada vez se hace más difícil aquí expresar el pensamiento. (8I)

Rama, por su parte, se lamenta desde París, en carta del I7 de abril de I983:

de modo que al desastre de nuestra salida (mala venta de un apartamento, dispersión de muebles y objetos, pérdida de un puesto universitario y de la biblioteca que teníamos) se ha agregado una espinosa situación. En fin, de todo se salió siempre y ocurrirá lo mismo con estos. Será mi tercer exilio (Venezuela, USA, los primeros) y desearía ardientemente que fuera el último. Tampoco tengo ya edad para muchos más. (58)

En carta del 8 de octubre de 1974, Candido describirá, desde São Paulo, su perspectiva sobre una situación que siendo ya nefasta para su época recobra validez para los lectores que hoy accedemos a este dialogo intelectual:

Después que nos separamos, el mundo empeoró mucho, y la situación brasileña también (...). Con el mundo entero girando hacia la derecha y la violencia, el destino de nuestra madre patria, tan pequeña $y$ débil, es precario. Pero estamos aquí estremeciéndonos. (73)

A pesar del inevitable vínculo con su presente, puede decirse que en estas cartas es el futuro mismo el que está en disputa: me refiero con esto a la Editorial Biblioteca Ayacucho como espacio de resistencia intelectual, tema predominante en el conjunto de las cartas:

hemos creado una Comisión (con patrocinio de la presidencia) destinada a publicar la Biblioteca Ayacucho (en conmemoración del sesquicentenario de la batalla que consolidó la independencia de América Hispánica) y que consistirá en una biblioteca cerrada de aproximadamente unos trescientos volúmenes donde queremos seleccionar los más importantes autores y obras, en la literatura, el pensamiento y la historia de Nuestra América (la española, portuguesa y francesa) desde sus orígenes hasta hoy, es decir, desde los poemas de Netzahualcoyotl hasta los grandes maestros de la literatura actual (Guimarães, Neruda, Carpentier, Borges, Drummond, etc.)

Contigo cuento para toda la parte brasileña.

(carta de Rama, Caracas I7 de septiembre de 1974:70)

La Editorial Biblioteca Ayacucho nació en 1974 y representó para nuestros autores la posibilidad de integrar un proyecto que se propuso la relectura de la tradición 
latinoamericana y su discusión con las problemáticas de la época. Haber incluido obras brasileñas abrió las puertas, para el mundo hispánico, de esa cultura, estableciendo un diálogo continental que pretendía afirmar un sistema literario para América Latina. Antonio Candido fue fundamental para la elección de las obras brasileñas que participaron originalmente de la Biblioteca, ${ }^{5}$ él también elaboró los prólogos de algunas de las obras escogidas como Memórias de un sargento de milícias y Ensayos literarios - compendio de la obra de Silvio Romero- Como autor, Candido publicó en la biblioteca Crítica radical. Rama fue el editor literario de la colección, hecho que cambió el tono de la interlocución entre Candido y Rama, siendo ahora una preocupación fundamental la discusión material entre editor y autor.

El conjunto epistolar incluye, a título de anexo, la correspondencia entre Rama y la reconocida esteta Gilda de Mello e Souza (I2 cartas). En ellas la discusión se centra en la edición y prólogo a Obra Escogida, de Mario de Andrade (1979).
El tono aquí será condescendiente, típico de viejos amigos que ahora comparten un proyecto editorial. Gilda le escribirá a Rama, desde São Paulo, en I de septiembre de 1976: "Soy, de hecho, una colaboradora incómoda, muy enredada en sus pretextos, pero cuando consigo desenredarme de la madeja de mis resistencias, trabajo con amor y sentido del deber» (I47). Como anexo también aparece el discurso de aceptación de Doctor honoris causa de la Universidad de la República, proferido por Antonio Candido, paratexto fundamental de interpretación del conjunto total de la obra.

Este epistolario se presenta como un testimonio particular de la historia intelectual del continente, a partir de un diálogo múltiple, que va de cuestiones a confesiones personales, pasando por documentos oficiales. Estas cartas dan forma al tránsito inestable entre la vida privada y la pública. La gran apuesta de esta publicación parece ser reconocer en la intimidad de la vida intelectual, en su vigencia, coordenadas de interpretación de nuestra actualidad.

5 Los ejemplares, dedicados a la literatura, a la cultura y a las artes brasileñas serán publicados en las décadas de 1970 y 1980: Casa-grande \& senzala, 1977 (v. 11); Memórias de un sargento de milícias, de Manuel Antonio de Almeida, 1977 (v. 25); Cuentos, de Joaquim M. Machado de Assis, 1978 (v. 33); Arte y arquitectura del Modenismo Brasileño (1917-1930), 1978 (v. 47); Dos novelas (Recuerdos del escribiente Isaías Caminha y El triste fin de Policarpo Quaresma, de Lima Barreto, 1978 (v. 49); Quincas Borba, de Machado de Assis, 1979 (v. 52); Obra Escogida, de Mario de Andrade, 1979 (v. 56); Los sertones, de Euclides da Cunha, 1980 (v. 79); Obra Escogida, de Oswald de Andrade, 1981 (v. 84) y Ensayos Literarios, de Silvio Romero, 1982 (v. 93). 
Referencias bibliográficas

- RAMA, Á. (2001). Diario: 1974-1983. Prólogo de Rosario Peyrou. Montevideo: Trilce.

- RIBEIRO, D. Y RAMA, Á. (2015). Diálogos latinoamericanos: correspondencia entre Ángel Rama, Berta y Darcy Ribeiro. Organización, estudios y notas Haydée Ribeiro Coelho y Pablo Rocca. São Paulo: Global Editora.

- RocCA, P. (2006). Ángel Rama, Emir Rodríguez Monegal y el Brasil: dos caras de un proyecto latinoamericano, 2006. Tese de Doutorado (Língua Espanhola e Literaturas Espanhola e Hispano-Americana). Faculdade de Filosofia, Letras e Ciências Humanas, Universidade de São Paulo, São Paulo. 